\title{
Home Gardens Contribute Significantly to Dietary Diversity in HIV/AIDS Afflicted Households in Rural Ghana
}

\author{
Susana Akrofi ${ }^{1,3,4}$, Inge D. Brouwer ${ }^{2}$, Lisa L. Price ${ }^{3}$ and Paul C. Struik ${ }^{4}$ \\ ${ }^{1}$ Plant Genetics Resources Research Institute-CSIR, P.O. Box 7, Bunso, E/R Ghana \\ ${ }^{2}$ Division of Human Nutrition, Wageningen University, Wageningen, The Netherlands \\ ${ }^{3}$ Department of Sociology of Consumers and Households, Wageningen University, \\ Wageningen, The Netherlands \\ ${ }^{4}$ Centre for Crop Systems Analysis, Wageningen University, Wageningen, The Netherlands
}

KEYWORDS Dietary. Diversity Score. Shannon-Wiener Index. Plant Species Diversity

\begin{abstract}
The study assessed the biodiversity in home gardens and evaluated its contribution to dietary diversity among HIV-positive and HIV-negative rural households in Eastern Region, Ghana. A cross-sectional survey of 32 HIVpositive and 48 HIV-negative households was conducted. Plant species cultivated in the home garden of each household and their abundance were documented. Shannon-Wiener index was estimated for each home garden. A dietary diversity score (DDS $=$ a count of food groups consumed) was determined with $D D S_{(+H G)}$ and without $D D S_{(-H G)}$ home garden products for each household using a 24-hour qualitative dietary recall. HIV-positive and HIVnegative households were compared using Student's $t$-tests and Fisher's exact tests. HIV-positive households showed a significantly higher $D D S_{(+H G)}$ than HIV-negative households (6.8 vs. 6.0). The $D D S_{(-H G)}$ did not differ between groups but there was a significant difference between $D D S_{(+H G)}$ and $D D S_{(-H G)}$ within groups. A higher $D D S$ in HIV-positive households was not associated with a higher Shannon-Wiener index. The contribution of food items from home gardens to DDS was significantly higher in HIV-positive (14.9\%) than in HIV-negative households (9.1\%). Home gardens contribute significantly to dietary diversity in HIV-positive rural households, although no significant change in plant species diversity was observed compared to HIV-negative households.
\end{abstract}

\section{INTRODUCTION}

Household food security is defined as the ability of a household to secure, either from its own production or through purchase, adequate food to meet the dietary needs of its members for a healthy and active life (Egal and Valstar 1999). The detrimental effect of HIV illness on food security of afflicted rural households in SubSaharan Africa is well-known (Barnett and Whiteside 2002; United Nations 2008). HIV/AIDS morbidity impacts on labour, rural household fields are neglected, cultivated areas are reduced and there is a shift from cultivating labour intensive, yet highly nutritious crops to less labour demanding and less nutritious crops leading to a reduction in the quantity and quality of agricultural produce available to the household (de Waal and Tumushabe 2003). Although the rural poor have always relied on diversity of crops

Corresponding author:

Paul C. Struik

Centre for Crop Systems Analysis,

P.O. Box 430 Wageningen University

6700 AK Wageningen, The Netherlands

Fax: + 31317485572 ;

E-mail: paul.struik@wur.nl and domestic livestock species to meet their basic needs, the home garden with its associated biodiversity is a neglected resource in adapting to increased nutritional needs and labour constraint due to HIV illness (Gari 2003). Salick (1997) observed that home garden cultivation became especially important in female-headed households when labour was constrained for field production. In that study, a greater diversity of crop species consisting of both major and minor crops was cultivated to supplement and supply a significant portion of the household's diet.

Dietary diversity, i.e. the number of foods consumed across and within food groups over a reference period, is widely recognized as a key indicator of nutrient adequacy (Ruel 2003; Mirmiran et al. 2004). Studies show that the overall nutritional quality of the diet improves with increasing number of food groups (Torheim et al. 2003; Steyn et al. 2006; Kennedy et al. 2007). Furthermore, consuming diverse diets offers protection against chronic diseases (Cummings and Bingham 1998), and enhances the immune system in people living with HIV to combat AIDS opportunistic diseases (Soyiri and Laar 2004).

In a study carried out to assess the biodiversity in home gardens and evaluate its contri- 
bution to dietary diversity among HIV-positive and HIV-negative rural households, the following hypotheses and sub-hypotheses were formulated:

(1) A higher number of HIV-positive rural household members will contribute in home garden cultivation than in HIV-negative households when field production decreases as a result of frequent ill-health or labour demand for care of the ill household member.

(i) Field production in HIV-positive rural households will decrease when frequent illhealth or labour demand for care of the ill household member increases.

(ii) A higher number of HIV-positive rural household members will contribute to home garden cultivation than in HIV-negative households when field production decreases.

(2) HIV-positive rural households will have higher home garden species diversity than HIV-negative households when the number of household members who contribute to home garden cultivation increases.

(i) HIV-positive households will cultivate a greater number of categories of plant species in home gardens than HIV-negative rural households when the number of household members who contribute to home garden cultiva-tion increases.

(ii) HIV-positive households will have higher home garden species diversity than HIVnegative households when a greater number of categories of plant species is cultivated in home gardens.

(3) HIV-positive rural households will have a higher dietary diversity compared with HIVnegative households when home garden species diversity increases.

(i) HIV-positive rural households will consume a higher number of food items from home gardens than HIV-negative households when home garden species diversity increases.

(ii) HIV-positive households will have a higher dietary diversity than in HIV-negative households when they consume a higher number of food items from the home gardens.

The study used data from a 24-hour qualitative recall of a cross-section of HIV-positive and HIV-negative households in some rural areas in the Eastern region of Ghana to test the above hypotheses.

\section{METHODOLOGY}

The cross-sectional study used a multidisciplinary approach combining social, plant and nutrition sciences. Data collection was carried out from $26^{\text {th }}$ October 2005 to $20^{\text {th }}$ February 2006 (postharvest season) in the Eastern Region, the administrative region in Ghana with the highest prevalence rate of HIV/AIDS (6.5\% compared to $3.1 \%$ national rate; Ghana AIDS Commission 2006). The high HIV prevalence in the region is attributed to the return of some Ghanaian females involved in commercial sex trade in neighbouring West African countries with higher HIV prevalence (Oppong 1998).

A home garden in this study is a small-scale supplementary food production system (Hoogerbrugge and Fresco 1993), located within the homestead or within 10 minutes walk from the homestead, continuously cultivated by and for household members, and comprising of a complex and diverse mixture of annual and perennial plants and livestock (Mohan et al. 2007). A household is defined as a group of persons who live together in the same house or compound and share the same house-keeping arrangement and are catered for as one unit (Ghana Statistical Service 2002).

\section{Subjects}

A purposive sample of $32 \mathrm{HIV}$-positive households and a random sample of 48 HIVnegative households each with a home garden were selected from 17 rural communities located in 12 districts in the Eastern Region of Ghana. HIV-positive households were recruited purposively owing to the difficulty in locating individuals living with HIV illness as a result of stigmatization. An HIV-positive household in this study refers to a household where at least one member suffered from confirmed HIV illness, whilst in a HIV-negative household no member was known to have HIV illness (UNAIDS 2008). HIV-positive households were identified through a nongovernmental association, the Association of Persons Living with HIV and AIDS (PLWHA) in three district hospitals of the Eastern Region of Ghana. The members of PLWHA comprised individuals from different parts of the country who had tested positive for HIV. A sample of three HIV-negative households was randomly selected from each of the 17 communities where the 
selected HIV-positive households resided based on a list of households with home gardens compiled with the help of community leaders. Three households which did not meet the criteria for a home garden were excluded.

Permission to conduct the research was obtained from the Eastern Regional Administration, the Regional Ministry of Health, Ministry of Agriculture and the Directors of Administration of the three hospitals. Household heads were asked for informed verbal consent for their household to participate in the study.

\section{Study Methods}

Demographic, socio-economic and home garden information were collected during household interviews using a questionnaire administered by the researcher in the local language (Twi). The demographic characteristics comprised age and sex of household members, household size, dependency ratio (ratio of number of household members younger than 15 years or older than 65 years to number of household members aged between 15 and 65 years); household type (sex of household head) and educational level (years of formal education) of household head. Socio-economic information included farming characteristics of the household head (part time or full time), number of adult household members (between 15 and 65 years of age) who contribute to home garden cultivation and to domestic livestock rearing and sources of household income. For home gardens, an inventory of the cultivated plant species was compiled and the number of individual plants of each species documented. The species diversity in each home garden was quantified using the Shannon-Wiener index $H^{\prime}=-\Sigma\left(p_{\mathrm{i}} \log p_{\mathrm{i}}\right)$, where $p_{i}$ is the relative abundance of occurrence of the $i$ th species in the home garden calculated as the proportion of the number of individuals of the $i$ th species to the total number of individuals (Kent and Cocker 1992). The plant species were also categorized by way of use: human food (vegetables, roots and tubers, fruits and spices), medicine and animal feed. The different kinds of domestic livestock reared in each home garden were recorded.

Household food intake was assessed by a qualitative recall of foods consumed by the household during the 24 hour preceding of the survey from the household member who prepared the previous day's meals. Foods were counted as the three main meals of the day; namely, breakfast, lunch and dinner, and fruits which were eaten between meals were also included. Foods consumed on multiple occasions during the previous 24 hours were counted only once. The dietary diversity score $(D D S)$ was calculated as the number of food groups consumed using the following food groups: cereals, vitamin A-rich vegetables and tubers; white tubers and roots; dark green leafy vegetables; other vegetables; vitamin A-rich fruits; other fruits; organ meat (iron rich); flesh meats; eggs; fish; legumes, nuts and seeds; milk and milk products; oils and fats and red palm products (FAO 2007). Food items obtained from the home garden were specified and a dietary diversity score was calculated with $D D S_{(+H G)}$ and without $D D S_{(-H G)}$ home garden products.

\section{Statistical Analysis}

The Statistical Package for Social Sciences (SPSS) version 14.0 was used for all statistical analyses. Descriptive analyses were used to summarize household and home garden characteristics; household consumption of food groups and household consumption of food items from home garden. HIV-positive and HIV-negative households were compared with regard to selected socio-demographic variables, home garden characteristics and dietary diversity scores using Student's $t$-tests. Not normally distributed data were log-transformed before analysis. The averages of the variables presented in the tables are based on back-transformed values (Philip and Cook 2000). Data pertaining to home garden management practices and household consumption of food groups were assessed in a descriptive manner by evaluating the proportion of each group of households using Fisher's exact test at $p<0.05$ level of significance.

\section{RESULTS}

\section{Household Characteristics}

HIV-positive household heads were significantly older (61 years), more likely to be female, had less formal education (six or more years of schooling) (56\%) and had a higher dependency ratio $(0.8)$ than heads of HIVnegative households. They cultivated a smaller 
area of field crop (0.6 ha), but showed no significant differences in the size of household, engagement in subsistence farming as a primary occupation or sources of income compared with HIV-negative households (Table 1).

\section{Home Garden Characteristics}

Table 2 shows that HIV-positive households did not differ significantly from HIV-negative households with respect to the Shannon-Wiener index, number of categories of plant species, kinds of domestic livestock reared and home garden area. No significant difference was found between the two groups in the proportion of households that solely consumed home garden produce or had free use of the home garden land. In HIVpositive households a significantly higher number of adult household members contributed to crop cultivation and domestic livestock rearing compared with HIV-negative households (2.7 vs. $1.9 ; 2.2$ vs. 1.5 , respectively) (Table 2 ).

\section{Household Consumption of Food Groups}

HIV-positive households consumed a diet with a higher dietary diversity score $(D D S)$ (6.8) compared with HIV-negative households (6.0) (Table 3). While HIV-positive households consumed food items from thirteen food groups, HIV-negative households consumed from twelve food groups (Table 4). None of the households

Table 1: Demographic and socio-economic profile of the households

\begin{tabular}{|c|c|c|c|c|}
\hline Variables $^{a}$ & $\begin{array}{l}\text { HIV-positive } \\
\quad(n=32)\end{array}$ & $\begin{array}{l}\text { HIV-negative } \\
\quad(n=48)\end{array}$ & $\begin{array}{l}95 \% \text { confidence } \\
\text { interval of the difference }\end{array}$ & $p$-value + \\
\hline \multicolumn{5}{|l|}{ Demographic information } \\
\hline Age of household head (years) & 60.50 & 53.72 & $3.65,11.50$ & 0.03 \\
\hline Household size (nr) & 6.34 & 5.77 & $-0.43, \quad 1.78$ & 0.20 \\
\hline Dependency ratio ${ }^{b}$ & 0.83 & 0.60 & $0.04, \quad 0.14$ & 0.04 \\
\hline $\begin{array}{l}\text { Formally educated household head }(\%) \\
\text { (six or more years of schooling) }\end{array}$ & 56 & 71 & - & 0.18 \\
\hline Female-headed household $(\%)$ & 66 & 31 & - & 0.00 \\
\hline Socio-economic information & & & - & \\
\hline Full time farming $(\%)$ & 50 & 48 & - & 0.86 \\
\hline Field crop area (ha) & 0.62 & 0.88 & $-0.46,-0.06$ & 0.01 \\
\hline Income sources (nr) & 2.28 & 2.35 & $-0.45, \quad 0.31$ & 0.70 \\
\hline
\end{tabular}

${ }^{a}$ Values are means or back-transformed from the means for log-transformed data unless mentioned otherwise

${ }^{b}$ Values are mean ratio of number of household members aged below 15 years and above 65 years to number of household members between 15 and 65 years old

$\dagger$-value of Student's t-test for difference between mean values and of Fisher's Exact test for difference between proportions

Table 2: Description of home gardens of the households

\begin{tabular}{|c|c|c|c|c|}
\hline Variables $^{a}$ & $\begin{array}{l}\text { HIV-positive } \\
\quad(n=32)\end{array}$ & $\begin{array}{l}\text { HIV-negative } \\
\quad(n=48)\end{array}$ & $\begin{array}{l}95 \% \text { confidence } \\
\text { interval of the difference }\end{array}$ & $p$-value $\dagger$ \\
\hline Shannon-Wiener diversity index & 1.19 & 1.30 & $-0.32,0.09$ & 0.30 \\
\hline Categories of plant species (nr) & 3.31 & 3.38 & $-0.41,0.39$ & 0.60 \\
\hline Kinds of domestic livestock (nr) & 1.69 & 2.01 & $-0.20,0.23$ & 0.59 \\
\hline Cultivated home garden area (ha) & 0.19 & 0.18 & $-0.05,0.05$ & 0.93 \\
\hline Age of home garden (years) & 8.47 & 8.63 & $-3.95,3.63$ & 0.94 \\
\hline $\begin{array}{l}\text { Adult household members } \\
\text { (aged between } 15 \text { and } 65 \text { years) who } \\
\text { contribute to home garden cultivation }\end{array}$ & $\begin{aligned} & 2.66 \\
(\mathrm{nr}) & \end{aligned}$ & 1.85 & $0.06,0.45$ & 0.01 \\
\hline $\begin{array}{l}\text { Adult household members } \\
\text { (aged between } 15 \text { and } 65 \text { years) } \\
\text { who contribute to domestic livestock } \\
\text { rearing (nr) }\end{array}$ & 2.21 & 1.53 & $0.01,0.55$ & 0.02 \\
\hline Free use of land $(\%)$ & 94 & 94 & - & 1.00 \\
\hline $\begin{array}{l}\text { Crop produce solely for household } \\
\text { consumption }(\%)\end{array}$ & 38 & 27 & - & 0.33 \\
\hline
\end{tabular}

${ }^{a}$ Values are means or back-transformed from the means for log-transformed data unless mentioned otherwise $\dagger$-value of Student's t-test for difference between mean values and p-value of Fisher's Exact test for differences between proportions 
in the two groups consumed organ meat or milk and milk products.

The majority of both HIV-positive and HIVnegative households consumed a cereal ( $84 \%$ and $73 \%$, respectively), vitamin A-rich vegetables and tubers ( $81 \%$ and $77 \%$, respectively), or white tubers and roots (94\% in both groups) the day before the survey. All households consumed vegetables other than dark green leafy vegetables, and fish (the relatively less expensive source of animal protein). A relatively small proportion of households in both groups consumed flesh meat, and eggs which are relatively expensive sources of protein foods compared to legumes: $3 \%$ (meat) $13 \%$ (eggs) and 38\% (legumes) for HIV-positive households and 4\%, 4\% and 23\% for HIV-negative households. Some form of oil or fat was consumed by both groups: HIV-positive $16 \%$ and HIV- negative households $10 \%$. A higher (but not significantly higher) proportion of HIV-positive households (47\%) consumed red palm products as palm nut pulp soup or sauce or red palm oil compared with HIV-negative households (31\%).

\section{Household Consumption of Food Items from Home Garden}

To clarify the contribution of home gardens to the dietary diversity score $(D D S)$, the $D D S$ including food items from the home garden $D D S_{(+H G)}$ and that without food items from the home garden $D D S_{(-H G)}$ were calculated (Table 3) and the percentages of households that consumed food from a food group obtained from the home garden were compared within and between the two groups. HIV-positive

Table 3: Contribution of home garden produce to Dietary Diversity Scores (DDS)

\begin{tabular}{|c|c|c|c|c|}
\hline Dietary score & $\begin{array}{l}H I V \text {-positive } \\
\quad(n=32)\end{array}$ & $\begin{array}{l}\text { HIV-negative } \\
(n=48)\end{array}$ & $\begin{array}{c}95 \% \text { confidence } \\
\text { interval of the difference }\end{array}$ & $p$-value $\dagger$ \\
\hline $\mathrm{DDS}_{(\mathrm{HG})}{ }^{\mathrm{a}}$ & $6.75 *$ & $6.00 *$ & 0.22 & 0.00 \\
\hline $\operatorname{DDS}_{(-\mathrm{HG})}{ }^{(+\mathrm{HG})}$ & 5.72 & 5.42 & -0.17 & 0.24 \\
\hline $\begin{array}{l}\text { Contribution of home garden } \\
\text { produce to DDS }(\%)^{b}\end{array}$ & 14.90 & 9.14 & $0.96,10.57$ & 0.02 \\
\hline
\end{tabular}

$\mathrm{DDS}_{(+\mathrm{HG})}$ - dietary diversity score including food items from home garden

$\mathrm{DDS}_{(\mathrm{HG})}$ - dietary diversity score excluding food items from home garden

a Values are means

${ }^{\mathrm{b}}$ Contribution of home garden to $\mathrm{DDS}: \mathrm{DDS}_{(+\mathrm{HG})}-\mathrm{DDS}_{(-\mathrm{HG})} / \mathrm{DDS}_{(+\mathrm{HG})} \times 100$

$\dagger$-value of Student's t-test for difference between mean values

* significantly different from $\operatorname{DDS}_{(-\mathrm{HG})}$ at $\mathrm{p}<0.001$

Table 4: Intake of food groups and food items from home garden by households

\begin{tabular}{|c|c|c|c|c|}
\hline \multirow[t]{2}{*}{ Food groups } & \multicolumn{2}{|c|}{ HIV-positive $(n=32)$} & \multicolumn{2}{|c|}{ HIV-negative $(n=48)$} \\
\hline & $\begin{array}{l}\text { Food group } \\
\text { consumed }\end{array}$ & $\begin{array}{l}\text { Food item from } \\
\text { home garden }^{b}\end{array}$ & $\begin{array}{l}\text { Food group } \\
\text { consumed }\end{array}$ & $\begin{array}{c}\text { Food item from } \\
\text { home garden }\end{array}$ \\
\hline Cereals & 84.4 & 0 & 72.9 & 0 \\
\hline Vitamin A-rich vegetables and tubers & 78.1 & 54.2 & 77.1 & 33.3 \\
\hline White tubers and roots & 93.8 & 26.7 & 93.8 & 13.3 \\
\hline Dark green leafy vegetables & 40.6 & 30.8 & 31.3 & 39.9 \\
\hline Other vegetables & 100 & 3.1 & 100 & 12.5 \\
\hline Vitamin A-rich fruits & $15.6^{*}$ & $60.2 *$ & 0 & 0 \\
\hline Other fruits & 21.9 & 42.9 & 10.4 & 60.5 \\
\hline Organ meat (iron-rich) & 0 & 0 & 0 & 0 \\
\hline Flesh meats & 3.1 & 0 & 4.2 & 0 \\
\hline Eggs & 12.5 & 75.2 & 4.2 & 43.8 \\
\hline Fish & 100 & 0 & 100 & 0 \\
\hline Legumes, nuts and seeds & 37.5 & 0 & 22.9 & 0 \\
\hline Milk and milk products & 0 & 0 & 0 & 0 \\
\hline Oils and fats & 15.6 & 0 & 10.4 & 2.1 \\
\hline Red palm products & 46.9 & $31.3 *$ & 31.3 & 10.4 \\
\hline
\end{tabular}


households showed a significantly higher $D D S_{(+H G)}(6.8)$ compared with HIV-negative households (6.0). The $D D S_{(-H G)}$ did not differ between groups, but there was a significant difference between $D D S_{(+H G)}$ and $D D S_{(-H G)}$ within groups. The contribution of food items from the home garden to the $D D S$ was significantly higher in HIV-positive (14.9\%) than in HIV-negative households $(9.1 \%)$ (Table 4).

With regard to the specific food groups consumed (Table 4), there were no major differences in most food groups although a higher proportion of HIV-positive households consumed cereals, vitamin A-rich vegetables and tubers, dark green leafy vegetables, other fruits, eggs, legumes, nuts and seeds, oils and fats and red palm products. A significant proportion of HIVpositive households consumed vitamin A-rich fruits which were not consumed by any HIVnegative household (16\% vs. $0 \%$ ). A significantly larger proportion of HIV-positive households obtained the vitamin A-rich fruits and red palm products (60\% and $31 \%$, respectively) from the home garden compared with HIV-negative households ( $0 \%$ and $10 \%$, respectively).

There was no correlation between the Shannon-Wiener index of home gardens and the dietary diversity score of the rural households studied $(\mathrm{r}=0.17 ; \mathrm{N}=80 ; p=0.14)$.

\section{DISCUSSION}

The study assesses the biodiversity in home gardens of HIV-positive and HIV-negative households in rural areas in the Eastern Region of Ghana, and evaluates the contribution of food items from these gardens to dietary diversity. This provided an insight into the contribution of home garden produce to dietary diversity as part of a study to determine the effect of HIV illness on management strategies in home garden cultivation in a rural setting in Southern Ghana.

\section{Household Characteristics}

The results presented in this study indicate that HIV-positive household heads are older, more likely to be female, their households have a higher dependency ratio and they cultivated a smaller area of field crop compared with HIV-negative households. Migration to urban areas often draws away the more dynamic youthful members of rural areas in Ghana and so the elderly form a higher proportion of the rural population of which a higher percentage are females. In Ghana, women normally marry men older than themselves, and added to the fact that females live longer than males in most societies many elderly women survive their husbands and often find themselves as household heads (United Nations 2001; Mba 2004). Moreover women being society's traditional caregivers, often carry the physical burden of providing AIDS care (D'Çruz 2003). As in many developing countries, the extended family in Ghana is a source of support and care for most people during illness and this is also the situation with HIV illness (Mwinituo 2006). Results of the current study confirm the findings of Booysen et al. (2004) that a higher proportion of HIV-positive households consists of extended-family members, while a relatively smaller proportion belongs to the nuclear family of the household head. The extended-family members included the brothers, sisters, nieces, daughters-in-law of the household head and their young dependents. The majority of the adult extended-family members had come to assist in caring for the ill household member. The higher dependency ratio in HIV-positive households is due to the presence of these young dependents in the household. In HIV-positive households labour constraints due to HIV illness or taking time off to attend to the HIV ill household member could account for the smaller area of field crop cultivated (de Waal and Tumushabe 2003).

\section{Home Garden Characteristics}

The participation in home garden cultivation tasks by some extended family members who had moved into HIV-positive households to assist in care giving might have resulted in the significantly higher number of productive adult household members who contributed to crop cultivation in home gardens and domestic livestock rearing than in HIV-negative households. This may imply a higher labour input in home garden cultivation in HIV-positive rural households and could show the importance attached to home garden cultivation. The home garden is an essential part of the food production system in rural areas in Ghana in supplementing household field production (Owusu et al. 1994).

Agro-ecological conditions are known to have great influence on plant species composition in home gardens (Shrestha et al. 2002). Most of the 
plant species recorded in home gardens are species that characterise the semi-deciduous forest zone of Ghana (Bennet-Lartey et al. 2001). Similar climatic conditions and farming practices across the 12 districts in the semi-deciduous forest zone where the home gardens were located may have contributed to the absence of a significant difference between HIV-positive and HIVnegative households in the Shannon-Wiener index and the number of categories of plant species in home gardens. The home gardens were rain fed and crops were cultivated mainly in the rainy season.

Vegetables cultivated in the home gardens were mainly consumed by households in both groups. In $62 \%$ of HIV-positive and $73 \%$ of HIVnegative households income obtained from the sale of chickens, sheep and goats reared and surplus home garden produce was used to purchase other food items not available in the home and also to provide other basic needs.

\section{Household Consumption of Food Groups}

There was minimum variation in the diet consumed by HIV-positive and HIV-negative households. The traditional Ghanaian diet consists of a staple dish of either a cereal, or a root and tuber crop accompanied by a sauce prepared from vegetables and at times with oil. Red palm oil, an important source of vitamin A, was relatively easily available to households for cooking, since in the preparation of palm nut pulp soup the excess oil is skimmed off the surface of the soup and used for preparation of sauces. Vegetables such as tomato and onions are commonly used in preparing soups and sauces and leafy vegetables are sometimes added. The diet is often supplemented with some protein food source of either animal or plant origin. All households consumed fish in their diet as fish constitutes the major source of protein intake in Ghana (Plahar et al. 1997). Fish was consumed fried, smoked, dried or in a salted and fermented form as a condiment in sauces. Consumption of fish is particularly high among subsistence groups and other groups with low purchasing power. Among a broad section of people in southern Ghana, meat, eggs, milk and poultry are consumed mostly on festive occasions, or are used to prepare food for important guests (Essuman 1992). Fruits are consumed to provide vitamins and minerals, and fibre (Oniang'o et al. 2003).

\section{Household Consumption of Food Items from Home Garden}

HIV-positive households consumed a diet with a higher dietary diversity score $(D D S)$ compared with HIV-negative households (Table 3 ), which may indicate a better quality of diet (Kant et al. 2000). When measured at household level, Hoddinott and Yohannes (2002) showed that an increase in $D D S$ is associated with an increase in household per capita energy intake, while studies in South Africa (Steyn et al. 2006), Kenya (Ruel 2003), and Mali (Torheim et al. 2003) show positive and significant associations of $D D S$ with micronutrient intake at the individual level. However, no consensus exists on what level of $D D S$ represents risk of nutrient inadequacy (Kennedy et al. 2007). Although the present study did not investigate whether the increase of $D D S$ was purposely done by the households, from a nutritional point of view an increase in energy intake would be beneficial to the individual living with HIV in view of the advice on $10 \%$ increase in energy intake (WHO 2003). Furthermore, the higher $D D S$ in HIV-positive households is attributed to the relatively larger number of households that consumed fruit and vegetables, particularly vitamin A-rich fruits and red palm products as shown in table 4 . As part of an education programme to improve the health of persons living with HIV, the importance of vitamins in the diet is emphasized at monthly meetings of the PLWHA. Vitamin A is essential for individuals living with HIV to strengthen the immune system and to reduce the severity of opportunistic infections and HIV disease progression. For other household members, it enhances the general level of health and immunity and reduces vulnerability to HIV illness (WHO 2003). Studies have indicated that vitamin A supplementation shows positive benefits to HIV-positive individuals but findings are not conclusive (Austin et al. 2006). However, consumption of (orange-fleshed) fruits and vegetables provide a readily available and reliable source of vitamin A and its consumption ought to be encouraged (Talukder et al. 2000; Schrimshaw 2002; Bruce Fife 2004; Faber and Van Jaarsveld 2007).

The plant species cultivated in the home garden offered an important source of micro nutrients and vitamins and contributed significantly to $D D S$ of HIV-positive households. The higher contribution of home garden produce to $D D S$ in 
HIV-positive households is attributed to a relative higher proportion of households that consumed food items from the home garden (Table 4). This result supports the findings of Salick (1997) that female-headed households depend on home gardens much more than the average household when labour is constrained for field production.

The absence of a significant difference between HIV-positive and HIV-negative households in the Shannon-Wiener index of the home gardens contradicts our working hypothesis. In the study, we anticipated significantly higher species diversity in home gardens of HIV-positive households and consequently a high $D D S$, but the results showed that the higher ShannonWiener index did not reflect in a higher $D D S$ in HIV-positive households. This implies that a rural household does not cultivate a greater diversity of plant species in the situation of HIV illness, but rather consumes more of the food items from the home garden. The study by Salick (1997) reported greater diversity in home gardens and a corresponding higher intake of food items from home gardens based on home gardens cultivated by only female-headed households whilst the present study assessed plant diversity in home gardens of both male-headed and female-headed households.

Biodiversity is essential for food security as it provides a diverse range of edible species used as sources of food. A diversity of foods from plants and animals remains the best means to achieve a balanced diet. Johns (2003) provided empirical evidence which supports the hypothesis that biodiversity could be equated with dietary diversity, which in turn could be equated with health. In the current study there was no clear trend between Shannon-Wiener index and $D D S$ which implies that household dietary diversity is not associated with home garden plant species diversity. This is however, the first empirical study that has explored the link between biodiversity in terms of Shannon-Wiener index and dietary diversity.

\section{Methodological Issues}

The identification and selection of HIVpositive households for the research posed a challenge due to the difficulty in identifying persons living with HIV because of the stigma attached to the disease (Agyeman 1993). Therefore, HIV-positive households were purposively sampled through an organization involved in AIDS counselling and care. A sample of 32 HIV-positive and 48 HIV-negative households located in 12 districts (out of the total number of 21) of the Eastern Region of Ghana was recruited for the survey. To ensure the representativeness of the sample, three HIV-negative households were randomly selected from a list of households compiled in each community where an HIV-positive resided. The selected HIV-negative households had no household member with confirmed HIV illness and had a home garden that satisfied the required criteria.

The study was conducted in the Eastern Region where $67 \%$ of its population live in rural areas and the prevalence of HIV has consistently been higher since 1986 when the first cases of HIV illness were reported (Ghana Statistical Service 2002; Ghana AIDS Commission 2004).

The small sample studied is a limitation in generalizing the findings of this study. In addition trends in differences which fit the hypotheses could have been significant with larger samples. The geographical location and socio-economic diversities of the sample are however appropriate for the study.

Despite the report that the 24-hour dietary recall method relies on respondents' memory and does not take care of day to day variation in food intake (Witschi 1998), the method was considered reliable to determine dietary diversity. This method is consistent with that used by Savy et al. (2006a) and Kennedy et al. (2007). The short recall period was expected to reduce recall bias which is likely to occur in a rural situation where the level of education is low (Swindale and OhriVachaspati 1999). Savy et al. (2006b) also showed in a study in Burkina Faso the longer the recall period, the greater the likelihood of underreporting.

\section{CONCLUSIONS}

The results of this study indicated that HIVpositive rural households cultivated significantly smaller area of field crop but a significantly higher number of adult household members contributed to home garden cultivation than in HIV-negative households. This shows the importance given to home garden cultivation in rural households in situation of HIV illness. The increase in labour input in home garden cultivation in HIV-positive households did not present a higher Shannon- 
Wiener index of the home garden compared with HIV-negative households. HIV-positive households consumed a diet with a higher dietary diversity score compared with HIV-negative households. Vitamin A-rich fruits and red palm products from the home garden contributed to the higher dietary diversity score in HIV-positive households. This suggests that rural households do not cultivate a greater diversity of plant species in home gardens in the situation of HIV illness, but rather consume relatively more food items of the essential food groups from their home gardens.

The higher dietary diversity score implies a better nutrition in HIV-positive households. However, given that consumption of diverse foods does not imply a nutritionally adequate diet per se, the nutritional benefit of the higher dietary diversity score in HIV-positive households requires further investigation. The cultivation of fruits and vegetables in home gardens should be promoted as part of a nutrition-based intervention for rural communities. This will not only increase the availability and consumption of diverse foods, including vitamin A-rich foods but also enhance the health status of persons, particularly those living with HIV.

\section{ACKNOWLEDGMENTS}

Funding for the study was provided by the Dutch Ministry of Foreign affairs. This work was performed in partial fulfilments of the requirement for a Ph.D thesis. The authors are grateful to PLWHA and the communities who participated in the study.

\section{REFERENCES}

Agyeman DK 1993. Families, neighbours and the AIDS epidemic. Paper presented at Workshop on Social Dimensions of HIV/AIDS in University of Cape Coast, Ghana, October 8 to 20, 1993.

Austin J et al. 2006. A community randomized controlled clinical trial of mixed carotenoids and micronutrient supplementation of patients with acquired immunodeficiency syndrome. Eur J Clin Nutr, 60: 12661276.

Barnett T, Whiteside A 2002. AIDS in the twenty-first century: Disease and Globalization. $2^{\text {nd }}$ Edition. New York: Palgrave Macmillan.

Bennet-Lartey SO, Ayernor GS, Markwei CM et al. 2001. Contribution of home gardens to in situ conservation of plant genetics resources in farming systems in Ghana. In: JW Watson, PB Eyzaguirre (Eds.): Proceedings of the $2^{\text {nd }}$ International Home Gardens
Workshop. Witzenhausen, Federal Republic of Germany, 17-19 July 2001, pp. 83-96.

Booysen F, Bachmann M, Matabesi Z, Meyer J 2004. The socio-economic impact of HIV/AIDS on households in South Africa: pilot study in Welkom and Qwaqwa, Free State Province. From <http:// www.jeapp.org.za/article.php?cat=allresearch\&id $=7$ (Retrieved January 25, 2010).

Bruce Fife ND 2004. Red palm oil. A daily dose of vitamins from cooking oil. From < http://www.coconutresearch center.org/article\%20red\%20palm\%20oil.htm> (Retrieved January 25, 2010)

Cummings JH, Bingham SA 1998. Diet and the prevention of cancer. $\mathrm{Br}$ Med J, 317:1636-1640.

D'Cruz P 2003. HIV/AIDS and Family Care. In: Family Care in HIV/AIDS: Exploring Lived Experience. New Delhi: Sage Publications Pvt Ltd, pp. 42-73.

De Waal A, Tumushabe J 2003. HIV/AIDS and food security for Africa. A report for DFID. From <http:/ /www.sarpn.org.za/documents/d0000235/index.php (Retrieved January 25 2010)

Du Guerny J 2002. Agriculture and HIV/AIDS. United Nations Development Program, Southeast Asia HIV and Development Project. From <http://www.hivpo licy.org/Library/HPP000057.pdf $>$ (Retrieved January 25,2010 ).

Egal F, Valstar A 1999. HIV/AIDS and Nutrition: Helping Families and Communities to Cope. Food Nutr \& Agric, 25: 20. From <www.fao.org/docrep/x4390t/ x4390t04> (Retrieved January 25, 2010).

Essuman KM 1992. The Role of Inland Fish in Food Consumption in West Africa: A Review and Annex Artisanal Fish Containers in Ghana: A Case Study. In: $\mathrm{F}$ Teutscher (Ed.): Proceedings of the symposium on post-harvest fish technology, October 21 to 22 1990, Cairo, Egypt. CIFA Technical Paper No. 19. pp. 122-240 Rome: Food and Agriculture Organization.

Faber M, Van Jaarsveld P 2007. The production of provitamin A-rich vegetables in home-gardens as a means of addressing vitamin A deficiency in rural African communities. J Sci Food Agr, 87: 366-377.

FAO (Food and Agriculture Organization) 2007. Household Dietary Diversity questionnaire. From <http://www.foodsec.org/tr/nut/hdd.pdf > (Retrieved January 25, 2010)

Gari J 2003. Agrobiodiversity strategies to combat food insecurity and HIV/AIDS impact in rural Africa. Advancing grassroots responses for nutrition, health and sustainable livelihoods. Population and Development Service, FAO, Rome, preliminary edition.

Ghana Statistical Service 2002. 2000. Population and Housing Census: Summary Report of Final Results. Accra: Ghana Statistical Service.

Ghana AIDS Commission 2004. Annual Report, 2004. Accra: Ghana AIDS Commission.

Ghana AIDS Commission 2006. Annual Report, 2006. Accra: Ghana AIDS Commission.

Hoddinott J, Yohannes Y 2002. Dietary diversity as food security indicator. FCND Discussion Paper 136. From <http://www.ifpri.org/divs/fend/dp/papers/ fcndp136.pdf> (Retrieved January 25, 2010).

Hoogerbrugge ID, Fresco LO 1993. Homegarden systems: agricultural characteristics and challenges. London: 
International Institute for Environment and Development. Gatekeeper Series no. 39.

Johns T 2003. Plant biodiversity and malnutrition: simple solutions to complex problems: theoretical basis for the development and implementation of a global strategy linking plant genetic resource conservation and human nutrition. AJFAND, 3(1). Bioline International open access journal. From <http:// www.bioline.org.br/abstract?id=nd03003\&lang=en $>$ (Retrieved January 25, 2010)

Kant AK, Schatzkin A, Graubard BI, Schairer C 2000. A prospective study of diet quality and mortality in women. JAMA, 283: 2109-2115.

Kennedy GL, Pedro MR, Seghieri C, Nantel G, Brouwer I 2007. Dietary diversity score is a useful indicator of micronutrient intake in non-breast-feeding Filipino Children. J Nutr, 137: 472-477.

Kent M, Cocker P 1992. Vegetation Description and Analysis: A Practical Approach. London: Belhaven Press.

Mba C 2004. Population ageing and survival challenges in rural Ghana. J Soc Devel Afr, 19: 90-112.

Mirmiran P, Azadbakht L, Esmaillzadeh A, Azizi F 2004. Dietary diversity score in adolescents-a good indicator of the nutritional adequacy of diets: Tehran lipid and glucose study. Asia Pacific J Clin Nutr, 3: 56-60.

Mohan S, Nair PKR, Long AJ 2007. An assessment of the ecological and socioeconomic benefits provided by the homegardens: A case study from Kerala, India. J. Sustain. Agric, 29(4): $135-153$.

Mwinituo PP, Mill JE 2006. Stigma associated with Ghanaian caregivers of AIDS patients. Western J Nurs Res, 28(4): 369-382.

Oniang'o R, Mutuku J, Malaba SJ 2003. Contemporary African food habits and their nutritional and health implications. Asia Pac J Clin Nutr, 12(3): 331-336.

Oppong JR 1998. A vulnerability interpretation of the geography of the HIV/AIDS in Ghana, 1986-1995. Prof Geogr, 50: 437-448.

Owusu JGK, Quarshie-Sam SJ, Nkyi KA, Oppong SK 1994. Indigenous African food crops and useful plants, their preparations for food and home gardens in Ghana. UNU/INRA Natural Resources Survey Series, No. B1.

Philip WC, Cook PA 2000. Using Statistics to Understand the Environment. New York: Routledge, Taylor \& Francis Group, pp. 58-64.

Plahar WA, Nti CA, Steiner-Aseidu M 1997. Fish consumption patterns in Ghana and fish quality at household level. Proceedings of a Workshop Organized by Artisanal Fish Processing and Applied Project. Food Research Institute, Accra.

Ruel MT 2003. Operationalizing dietary diversity: a review of measurement issues and research priorities. J Nutr, 133: 3911S-3926S.

Salick J 1997. Subsistence and the single woman among the Amuesha of the Upper Amazon, Peru. In: CE Sachs (Ed.): Women Working the Environment. Washington DC: Taylor and Francis, pp. 139-152.

Savy M, Martin-Prével, Traissac P, Eymard-Duvernay S, Depeuch F 2006a. Dietary diversity scores and nutritional status of women change during seasonal food shortage in rural Burkina Faso. J Nutr, 136: $2625-2632$.
Savy M, Martin-Prével Y, Traissac P, Delpeuch F 2006b. Measuring dietary diversity in rural Burkina Faso: Comparison of a 1-day and a 3-day dietary recall. Pub Health Nutr, 10: 71-78.

Schrimshaw NS 2002. Nutritional potential of red palm oil for combating vitamin A deficiency. Food Nutr Bull, 21: 195-201.

Shrestha PRRB, Rana G, Shapit B 2002. Home gardens in Nepal: Status and scope for research and development. In: JW Watson, PB Eyzaguirre (Eds.): Contribution of Home Gardens to in situ Conservation of Plant Genetic Resources. Rome: International Plant Genetic Resources Institute. From <http://www. bioversityinternational.org/fileadmin/.../publications/ pdf/753.pdf> (Retrieved January 25, 2010).

Soyiri IN, Laar AK 2004. Dietary Diversity Approach: A Key Component to the Management of HIV/AIDS Patients in Ghana. International Conference on AIDS, abstract no. D11497; 15th International Conference on AIDS, Bangkok, Thailand, July 11 to 16, 2004.

Steyn NP, Nel JH, Nantel G, Kennedy G, Labadarios D 2006. Food variety and dietary diversity scores in children: are they good indicators of dietary adequacy? Pub Health Nutr, 9: 644-650.

Swindale A, Ohri-Vachaspati P 1999. Measuring Household Food Consumption: A Technical Guide. Washington, DC: Agency for International Development, Academy for Educational Development.

Talukder A, Kiess L, Huq N, de Pee S, Darnton-Hill I, Bloem MA 2000. Increasing the Production and Consumption of Vitamin A-Rich Fruits and Vegetables: Lessons Learned in Taking the Bangladesh Homestead Gardening Programme to a National Scale. Food Nutr Bull, 21: 165-172.

Torheim LE, Barikmo I, Parr CL, Hatløy A, Ouattara F, Oshaug A 2003. Validation of food variety as an indicator of diet quality assessed with a food frequency questionnaire for Western Mali. Eur J Clin Nutr, 57: 283-1291.

United Nations 2001. World population prospects, the 2000 revision: Highlights. From <http://www.un.org/ esa/population/publications/wpp2002/WPP2002HIGHLIGHTSrev1.PDF> (Retrieved January 25, 2010).

UNAIDS (The Joint United Nations Programme on HIV/ AIDS) 2008. From <http://data.unaids.org/pub/ Manual/2008/JC1336_unaids_terminology_ guide _ en.pdf. (Retrieved January 25, 2010).

United Nations 2008. The impact of HIV/AIDS epidemic on agriculture. From <http://www.un.org/esa/popula tion/publications/AIDSimpact/8_Chap_V. pdf $>$ (Retrieved January 25, 2010).

Vecchia CL, Munoz SE, Braga C, Fernandez E, Decarli A 1997. Diet diversity and gastric cancer. Int J Cancer, 72: 255-257.

Witschi JC 1998. Short term recall and recording methods. In: W Walter (Ed.): Nutritional Epidemiology. Second Edition Oxford University Press, pp. 63-86.

WHO (World Health Organization) 2003. Nutrient requirements for people living with HIV/AIDS: report of a technical consultation. From <http://www.who. int/nutrition/publications/Content_nutrient_require ments.pdf (Retrieved January 25, 2010). 